\title{
HUBUNGAN ANTARA DUKUNGAN KELUARGA DENGAN GANGGUAN CITRA TUBUH PADA PENDERITA KUSTA
}

\author{
Endang Mei Yunalia, S.Kep Ns, M.Kep \\ Tata Mahyuvi \\ Prodi Ilmu Keperawatan Fakultas Ilmu Kesehatan Universitas Kadiri \\ Email: yunalia_blitar@yahoo.co.id
}

\begin{abstract}
Leprosy is cronic disease caused by Mycobacterium leprae. Leprosy is not only physical disease but it also influence patien's mental, social and economic. The purpose of this research was to identify the correlation between family support with body image disturbance on leprosy patients. This research is analytic correlation research wich used a cross sectional design. Sampling technique used purposive sampling and the sample consisted of 78 respondent. The result of this research most a half from respondent who has minimal family support have a negative body image $(34,6 \%)$. Based on Contingency Coefficient test can get P-value 0,04<0,05, with Coefficien Correlation 0,353, so HO is refused and $\mathrm{H} 1$ accepted, it means that there is any correlation between family support with body image disturbance on leprosy patients. Based on the result of this research, its expected the family should be given a good support. Because with good family support patients can be motivated, so that patients receive the conditions that occur and not impaired body image.
\end{abstract}

Key word: Leprosy, Body Image, Family Support

\section{PENDAHULUAN}

Penyakit kusta atau leprae atau disebut juga Morbus Hansen adalah penyakit menular yang bersifat kronis yang disebabkan oleh bakteri Mycobacterium Leprae, melalui kulit dan mukosa hidung (Samsudrajat, 2012). Masyarakat yang belum mengerti dengan jelas tentang penyakit kusta menganggap suatu penyakit yang sangat menakutkan. Penyakit kusta menimbulkan masalah yang sangat kompleks oleh karena adanya ulserasi, mutilasi dan deformitas. Dari segi non medis, penanganan mental, sosial, psikologi, dan ekonomi bagi penderita sangat penting, sehingga memerlukan suatu penanganan yang serius (Djuanda, 2011).

Data menurut WHO (Word Health Organisation) jumlah kasus baru kusta di dunia pada tahun 2011 adalah sekitar 219.075. Dari jumlah tersebut paling banyak terdapat di region Asia Tenggara
(160.132) diikuti region Amerika (36.382), region Afrika (12.673), dan sisanya berada di region lain di dunia. Indonesia menduduki peringkat ketiga dunia setelah India dan Brazil. Pada tahun 2010 di Indonesia ditemukan 17.012 kasus baru, 1.822 atau $10,71 \%$ diantaranya, ditemukan sudah dalam keadaan cacat tingkat II (cacat yang tampak). WHO juga mencanangkan Global Strategy for Further Reducing the Disease Burden Due To Leprosy 2011-2015 yaitu target global yang hendak dicapai tahun 2015 yaitu penurunan $35 \%$ angka cacat yang kelihatan (tingkat II) pada tahun 2015.

Pada tahun 2011 kasus kusta Provinsi Jawa Timur menduduki urutan pertama di Indonesia, penemuan kasus baru di Jawa Timur sebanyak 5284 kasus atau sekitar 1/3 dari jumlah seluruh penderita baru di Indonesia. Penderita penyakit kusta menyebar hampir ada di daerah Jawa Timur. Adapun penurunan kasus kusta 
tahun 2012 tercatat 4.842 penderita (Dinkes Propinsi Jawa Timur, 2013).

Hasil survey pendahuluan yang didapatkan di Rumah Sakit Kusta Kediri tanggal 27 Oktober 2015, 3 dari 10 pasien kusta tidak mengalami gangguan citra tubuh dan 7 pasien mengalami gangguan citra tubuh(body image). Pasien kusta yang mengalami gangguan citra tubuh mengatakan dalam menghadapi masalah yang ada pada diri mereka merasa malu dengan bentuk tubuhnya dan merasa canggung dan khawatir terhadap keadaan tubuhnya seta mengalami masalah psikologi yang serius, sehingga mereka sangat membutuhkan dukungan dari keluarganya. Hal ini menunjukkan gangguan citra tubuh (body image) pada beberapa pasien kusta di Rumah Sakit Kusta Kediri, sehingga merasa tidak percaya diri, malu dan khawatir akan tubuhnya sehingga dapat diambil suatu permasalahan yaitu masih tingginya gangguan citra tubuh (body image) pada penderita kusta.

\section{METODE PENELITIAN}

Desain yang digunakan dalam penelitian adalah analitik korelasional dengan pendekatan cross sectional study. Besar sampel dalam penelitian ini sebanyak 78 pasien kusta yang dipilih dengan teknik nonprobality sampling. Instrumen untuk pengukuran adalah variabel menggunakan lembar kuesioner. Data yang telah terkumpul dianalisa dengan menggunakan uji koefisienen kontingensi dengan $\alpha=0,05$.

\section{Hasil}

Tabel 1.1 Distribusi Frekuensi responden berdasarkan jenis kelamin

\begin{tabular}{cccc}
\hline No & $\begin{array}{c}\text { Jenis } \\
\text { Kelamin }\end{array}$ & Frekuensi & Prosentase \\
\hline 1. & Laki-laki & 52 & 66,7 \\
2. & Perempuan & 26 & 33,3 \\
\hline & Jumlah & $\mathbf{7 8}$ & $\mathbf{1 0 0}$ \\
\hline
\end{tabular}

(Sumber: Data Primer, 2015)

Berdasarkan tabel 1.1 di atas dapat diinterprestasikan bahwa sebagian besar responden yaitu sebanyak 52 orang $(66,7 \%)$ berjenis kelamin laki-laki

Tabel 1.2 Distribusi Frekuensi responden berdasarkan usia responden

\begin{tabular}{llcc}
\hline No & $\begin{array}{l}\text { Usia } \\
\text { (tahun) }\end{array}$ & Frekuensi & Prosentase \\
\hline 1. & $<20$ & 3 & 3,8 \\
2. & $20-40$ & 29 & 37,2 \\
3. & $41-60$ & 35 & 44,9 \\
4. & $>60$ & 11 & 14,1 \\
\hline Jumlah & $\mathbf{7 8}$ & $\mathbf{1 0 0}$ \\
\hline
\end{tabular}

(Sumber: Data Primer, 2015)

Berdasarkan tabel 1.2 di atas dapat diinterprestasikan bahwa sebagian besar responden yaitu sebanyak 35 orang $(44,9 \%)$ berusia $41-60$ tahun.

Tabel 1.3 Distribusi Frekuensi responden berdasarkan pekerjaan responden

\begin{tabular}{llcc}
\hline No & Pekerjaan & Frekuensi & Prosentase \\
\hline 1. & Pegawai & 3 & 3,8 \\
& negeri & & \\
2. & Swasta & 36 & 37,2 \\
3. & Tidak & 39 & 50,0 \\
& Bekerja & & \\
\hline Jumlah & $\mathbf{7 8}$ & $\mathbf{1 0 0}$ \\
\hline
\end{tabular}

(Sumber: Data primer, 2015)

Berdasarkan tabel 1.3 di atas dapat diinterprestasikan bahwa setengah dari responden yaitu sebanyak 39 orang $(50,0 \%)$ tidak bekerja.

Tabel 1.4 Distribusi Frekuensi responden berdasarkan pendidikan responden

\begin{tabular}{llcc}
\hline No & Pendidikan & Frekuensi & Prosentase \\
\hline 1. & $\begin{array}{l}\text { Pendidikan } \\
\text { dasar }\end{array}$ & 53 & 67,9 \\
2. & $\begin{array}{l}\text { Pendidikan } \\
\text { menengah }\end{array}$ & 22 & 28,2 \\
3. $\quad \begin{array}{l}\text { Pendidikan } \\
\text { tinggi }\end{array}$ & 3 & 3,8 \\
\hline Jumlah & $\mathbf{7 8}$ & $\mathbf{1 0 0}$ \\
\hline
\end{tabular}

(Sumber: Data primer, 2015)

Berdasarkan tabel 1.4 di atas dapat diinterprestasikan bahwa sebagian besar responden yaitu sebanyak 53 orang ( $67,8 \%$ ) memiliki pendidikan dasar. 
Tabel 1.5 Distribusi Frekuensi responden berdasarkan dukungan keluarga

\begin{tabular}{cccc}
\hline No & $\begin{array}{c}\text { Dukungan } \\
\text { keluarga }\end{array}$ & Frekuensi & Prosentase \\
\hline $\mathbf{1 .}$ & Kurang & 33 & 42,3 \\
2. & Cukup & 13 & 16,7 \\
3. & Baik & 32 & 41,0 \\
\hline & Jumlah & 78 & $\mathbf{1 0 0}$ \\
\hline
\end{tabular}

Sumber: Data primer, 2015)

Berdasarkan tabel 1.5 di atas dapat diinterprestasikan bahwa hampir setengahnya responden yaitu sebanyak 33 orang $(42,3 \%)$ mengalami tingkat dukungan keluarga kurang.

Tabel 1.6 Distribusi $\quad$ Frekuensi Responden Berdasarkan Citra Tubuh Responden

\begin{tabular}{cccc}
\hline No & $\begin{array}{c}\text { Citra } \\
\text { Tubuh }\end{array}$ & Frekuensi & Prosentase \\
\hline $\mathbf{1 .}$ & Negatif & 47 & 60,3 \\
$\mathbf{2 .}$ & Positif & 31 & 39,7 \\
\hline Jumlah & $\mathbf{7 8}$ & $\mathbf{1 0 0}$ \\
\hline
\end{tabular}

(Sumber: Data primer, 2015)

Berdasarkan tabel 1.6 di atas dapat diinterprestasikan bahwa sebagian besar responden yaitu sebanyak 47 orang $(60,3 \%)$ memiliki citra tubuh negatif

Tabel 1.7 Tabulasi Silang Hubungan Antara Dukungan Keluarga dengan Citra Tubuh

\begin{tabular}{lcccccc}
\hline $\begin{array}{l}\text { Dukungan } \\
\text { Keluarga }\end{array}$ & \multicolumn{3}{c}{ Citra Tubuh } \\
& Negatif & \multicolumn{2}{c}{ Positif } & \multicolumn{2}{c}{ Jumlah } \\
\cline { 2 - 7 } & $\mathbf{F}$ & $\mathbf{\%}$ & $\mathbf{F}$ & $\mathbf{\%}$ & $\sum_{1}$ & $\mathbf{\%}$ \\
& & & & & $\mathbf{F}$ & \\
\hline Kurang & 27 & 34,6 & 6 & 7,7 & 33 & 42,3 \\
Cukup & 6 & 7,7 & 7 & 9,0 & 13 & 16,7 \\
Baik & 14 & 17,9 & 18 & 23,1 & 32 & 41,0 \\
\hline P value = 0,04 & \multicolumn{9}{c}{$\mathbf{0 , 0 5}$} \\
\hline koefisien kontingensi $=0,353$ \\
\hline
\end{tabular}

Berdasarkan tabel 1.7 dapat diketahui bahwa hampir setengah dari responden yaitu sebanyak 27 orang $(34,6 \%)$ mempunyai tingkat dukungan keluarga kurang mengalami gangguan citra tubuh.

\section{PEMBAHASAN Dukungan Keluarga}

Berdasarkan dari hasil penelitian, pada tabel 1.5 dapat diketahui bahwa prosentase kategori dukungan keluarga pada pasien kusta menunjukkan bahwa hampir setengahnya pasien kusta pada penelitian ini dukungan keluarga kurang yaitu sebanyak 33 orang $(42,3 \%)$.

Dukungan keluarga adalah bantuan yang bermanfaat secara emosional dan memberikan pengaruh positif yang berupa informasi, bantuan instrumental, emosi, maupun penilaian yang diberikan oleh anggota keluarga yang terdiri dari suami, istri, orang tua, maupun saudara lainnya.

Dukungan keluarga adalah dukungan berupa dukungan sosial keluarga internal, seperti dukungan suami/istri atau dukungan dari saudara kandung atau dukungan sosial keluarga eksterna (Friedman,1998). Menurut Kene (1998) dalam Friedman (1998) mendefinisikan dukungan keluarga sebagai suatu proses hubungan antara keluarga dengan lingkungan sosial. Keluarga memakaikan suatu peran yang bersifat mendukung selama masa penyembuhan dan pemulihan (Subekti, 2005).

Analisa peneliti, didukung teori Friedman (1998) tentang dukungan keluarga bahwa dukungan keluarga sangat penting karena memberikan pengaruh positif dan motivasi kepada pasein kusta sehingga pasien kusta dengan adaya dukungan keluarga yang baik dapat menerima kondisi yang terjadi.

Berdasarkan penelitian, pada tabel 1.1 didapatkan bahwa sebagian besar resonden berjenis kelamin laki-laki sebanyak 52 responden $(66,7 \%)$. Dari 52 responden tersebut 22 responden mengalami dukungan keluarga kurang. Karena pada laki-laki yang mempunyai dukungan keluarga kurang mereka lebih tidak terbuka mengenai apa yang dideritanya sehingga keluarga menjadi 
tidak tahu dengan detail sehingga keluarga kurang memberi dukungan.

Berdasarkaan penelitian, pada tabel 1.2 didapatkah bahwa sebagian besar responden yaitu sebanyak 35 orang $(44,9 \%)$ berusia 41-60 tahun dari 35 orang tersebut 12 orang mengalami dukungan keluarga kurang. Pada responden yang berusia 41-60 tahun lebih jarang menceritakan dengan keluarganya sehingga keluarga jarang mengetahui tentang penyakit yang diderita sehingga dukungan kelarganya sebagian besar kurang.

Kelas ekonomi juga dapat mempengaruhi dukungan keluarga, yaitu meliputi tingkat pendapatan dan pekerjaan keluarga (Friedman,1998). Berdasarkan dari hasil penelitian, pada tabel 1.3 diatas menggambarkan bahwa setengah dari responden tidak bekerja yaitu sebanyak 39 orang $(50,0 \%)$. Dari 39 responden tersebut 20 responden mengalami dukungan keluarga kurang. Dengan banyaknya responden yang tidak bekerja menyebabkan tingkat sosial ekonomi keluarganya menjadi lemah, sehingga keluarga lebih memikirkan bagaimana memenuhi kebutuhannya dari pada memikirkan pemberian dukungan keluarga sehingga responden mempunyai tingkat dukungan keluarga kurang.

Tingkat pendidikan menentukan kemampuan seseorang memanfaatkan pengetahuan dan kesepakatan pengambilan keputusan dalam mengatasi masalah kesehatan yang dihadapinya sehingga tingkat pendidikan keluarga berpengaruh dalam pemberian dukungan terhadap keluarga (Notoatmojo, 2003).

Berdasarkan dari hasil penelitian, pada Tabel 1.4 diatas diketahi bahwa sebagian besar responden berpendidikan dasar yaitu sebanyak 53 orang $(67,9 \%)$. Dari 53 orang tersebut 24 orang mengalami dukungan keluarga kurang. Pengetahuan mereka rendah tentang penyakit kusta serta berkaitan dengan tindakan pencarian pengobatan. Rendahnya pendidikan dan pengetahuan mengakibatkan lambannya pencarian pengobatan dan diagnosis penyakit, hal ini mengakibatkan dukungan keluarga pada pasien kusta tidak bisa maksimal dan penyakit kusta semakin bertambah parah.

Peneliti menyimpulkan, bahwa dukungan keluarga kepada anggota keluarga yang lain sangatlah penting, terutama untuk menjaga kondisi psikologis anggota keluarga yang mrngalami gangguan, baik itu gangguan fisik maupun gangguan psikologis.

\section{Citra Tubuh Penderita Kusta}

Berdasarkan hasil penelitian pada tabel 1.6 dapat diketahui bahwa prosentase kategori citra tubuh pasien kusta di UPT Rumah Sakit Kusta Kediri Tahun 2015 yaitu sebanyak 47 orang responden $(60,3 \%)$ mengalami gangguan citra tubuh/ menggunakan citra tubuh negatif.

Citra tubuh membangun sebuah kompleks yang didefenisikan "persepsi, pikiran dan perasaan mengenai pengalaman tubuh" yang tertanam dan dibentuk dalam konteks sosial budaya kita tidak hanya menyediakan rasa diri, citra tubuh juga mempengaruhi bagaimana kita berpikir, bertindak dan berhubungan dengan orang lain, yang tiba-tiba perubahan dalam satu penampilan fisik sebagai hasil dari pekerjaan yang berhubungan dengan amputasi dapat hadir signifikan dan kompleks sebagai tantangan psikologis (Wald \& Alvaro, 2004).

Gangguan citra tubuh (body image) adalah perubahan persepsi tentang tubuh yang diakibatkan oleh perubahan ukuran, bentuk, struktur, fungsi, keterbatasan, makna dan objek (Harnawatiaj, 2008).Gangguan citra tubuh biasanya melibatkan distorsi dan presepsi negatif tentang penampilan fisik mereka. Perasaan malu yang kuat, kesadaran diri dan ketidaknyamanan sosial sering menyertai penafsiran ini. Sejumlah perilaku menghindar sering digunakan untuk menekan emosi dan pikiran negatif, 
seperti visual menghindari kontak dengan sisa ektremitas dan menyembunyikan sisa ekstremitas lain. Pada akhirnya reaksi negatif ini dapat mengganggu proses rehabilitasi dan berkontribusi untuk meningkatkan isolasi sosial (Wald \& Alvaro, 2004).

Adapun faktor-faktor yang mempengaruhi citra tubuh diantaranya dukungan keluarga, jenis kelamin, usia, pekerjaan, pendidikan dan tingkat pengetahuan (Azwar, 2012).

Berdasarkan penelitian, pada tabel 1.1 didapatkan bahwa sebagian besar pasien kusta berjenis kelamin laki-laki sebanyak 52 responden $(66,7 \%)$. Dari 52 orang tersebut 31 orang mengalami gangguan citra tubuh.Hal ini membuktikan bahwa laki-laki lebih banyak dan sebagian besar mengalami gangguan citra tubuh. Lakilaki mengalami gangguan citra tubuh dikarenakan mereka kurang menerima dengan keadaan yang terjadi karena dengan keadaan mereka akan mengganggu aktifitas mereka.

Berdasarkaan penelitian, pada tabel 1.2 didapatkah bahwa sebagian besar responden yaitu sebanyak 35 orang $(44,9 \%)$ berusia 41-60 tahun. Dari 35 orang tersebut 18 orang mengalami gangguan citra tubuh. Hal ini berkaitan dengan tumbuh kembang dimana seseorang akan merasakan perubahan pada dirinya seiring dengan bertambahnya usia serta adanya penyakit kusta yang diderita. Tidak jarang seseorang menanggapinya dengan respon negatif. Ketidakpuasan yang dirasakan seseorang pasien kusta yang mengalami perubahan bentuk tubuh akibat bertambahnya usia serta keterbatasan dari penderita penyakit kusta yang diderita sehingga menyebabkan gangguan citra tubuh.

Berdasarkan dari hasil penelitian, pada tabel 1.3 diatas menggambarkan bahwa setengah dari responden tidak bekerja yaitu sebanyak 39 orang $(50,0 \%)$. Dari 39 orang tersebut 26 orang mengalami gangguan citra tubuh. Dengan lemahnya tingkat ekonomi pasien tidak mampu melakukan perawatan dan pengobatan pada dirinya secara maksimal dikarenakan keterbatasan biaya untuk melakukan perawatan dan pengobatan secara maksimal sehingga pasien kusta mengalami gangguan citra tubuh.

Berdasarkan dari hasil penelitian, pada Tabel 1.4 diatas diketahui bahwa sebagian besar responden berpendidikan dasar yaitu sebanyak 53 orang $(67,9 \%)$. Dari 53 orang tersebut 36 orang mengalami gangguan citra tubuh. Berkaitan dengan rendahnya tingkat pendidikan sebagian besar pasien kusta merupakan salah satu faktor yang mempengaruhi pembentukan sikap seseorang mengenai citra tubuh. Sehingga dengan kurangnya pengetahuan tentang penyakit kusta yang diderita pasien tidak bisa melakukan perawatan dirinya secara maksimal sehingga menyebabkan gangguan citra tubuh.Berdasarkan teori dan fakta diatas diketahui bahwa faktor pendidikan berperanan penting dalam mempengaruhi citra tubuh responden, dengan pendidikan yang tinggi maka tingkat pengetahuan responden akan lebih luas sehingga dapat menerima keadaan yang ada pada tubuhnya dan begitu sebaliknya.

Penderita kusta harus dilakukan perawatan yang maksimal dan motivasi sehingga pasien kusta tidak mengalami gangguan citra tubuh.

\section{Hubungan Antara Dukungan Keluarga dengan Gangguan Citra Tubuh}

Analisis untuk mengetahui hubungan antara dukungan keluarga dengan gangguan citra tubuh pada penderita kusta menggunakan korelasi koefisien kontingensi dan data yang telah dikumpulkan dianalisis, dan diperoleh nilai $p$ value $=0,04(p<\alpha)$, karena $p$ value $<\alpha(0,05)$ maka dapat disimpulkan H0 ditolak dan $\mathrm{H} 1$ diterima, sehingga dapat disimpulkan bahwa ada hubungan antara dukungan keluarga dengan gangguan citra tubuh pada penderita kusta. Nilai Koefisien Kontingensi $=0,353$ yang 
diartikan kekuatan hubungan dalam kategori cukup artinya menunjukkan bahwa adanya korelasi antara tingkat dukungan keluarga dengan gangguan citra tubuh pada penderita kusta.

Berdasarkan hasil penelitian, tabulasi silang pada tabel 1.7 antara dukungan keluarga dengan citra tubuh dapat diketahui bahwa hampir dari setengah responden yaitu sebanyak 33 orang $(42,3 \%)$ mempunyai tingkat dukungan keluarga yang kurang, 27 orang diantaranya $(34,6 \%)$ mengalami gangguan citra tubuh dan 6 orang lainnya $(7,7 \%)$ mengalami citra tubuh positif. Hampir dari setengah responden yaitu sebanyak 32 orang $(41,0 \%)$ mempunyai tingkat dukungan keluarga baik, 14 diantaranya mengalami gangguan citra tubuh dan 18 mengalami citra tubuh positif.

Salah satu faktor yang mempengaruhi gangguan citra tubuh adalah dukungan keluarga. Faktor-faktor yang mempengaruhi pembentukan sikap seseorang mengenai citra tubuh adalah pengalaman pribadi, kebudayaan, pendidikan, serta orang lain yang dianggap penting (keluarga). Dimana keluarga dapat memberikan dorongan dan motivasi kepada pasien kusta yang mengalami gangguan citra tubuh (body image) ke arah pemecahan masalah. Dukungan keluarga dapat meningkatkan percaya diri pada pasien kusta yang mengalami gangguan citra tubuh (body image), sehingga pasien kusta tersebut menerima keadaan tubuhnya sesuai dengan kondisi yang terjadi (Azwar, 2012).

Seorang penderita kusta yang mengalami gangguan citra tubuh membutuhkan adaptasi dan dukungan dari orang lain disekitarnya untuk dapat menerima kondisinya yang sekarang. Faktor pendukung seperti keluarga, teman, dan rekan kerja yang akan mendengarkan dan memberikan nasihat dan dukungan emosional akan sangat bermanfaat bagi seseorang yang mengalami stress termasuk penderita kusta. Faktor pendukung dapat mengurangi reaksi stress dan meningkatkan kesejahteraan fisik dan mental (Keliat, 2009).

Faktor dukungan keluarga berperan penting dalam mempengaruhi citra tubuh pasien kusta. Dukungan keluarga adalah suatu dukungan yang diberikan oleh sesorang atau sekelompok orang kepada penderita penyakit yang bersifat timbal balik, umpan balik, dan adanya keterlibatan emosional. Keluarga dapat memberikan dorongan dan motivasi kepada pasien kusta yang mengalami gangguan citra tubuh (body image) ke arah pemecahan masalah. Dukungan keluarga dapat meningkatkan percaya diri pada pasien kusta yang mengalami gangguan citra tubuh (body image), sehingga pasien kusta tersebut menerima keadaan tubuhnya sesuai dengan kondisi yang terjadi.

Hasil penelitian membuktikan bahwa terjadinya gangguan citra tubuh diakibatkan oleh kurangnya dukungan keluarga. Hampir setengah dari responden yaitu sebanyak 27 orang $(34,6 \%)$ mengalami tingkat dukungan keluarga kurang dan mengalami gangguan citra tubuh. Hal ini dikarenakan keluarga kurang memberi dorongan dan motivasi kepada pasien kusta sehingga menyebabkan terjadinya gangguan citra tubuh. Tetapi, 6 responden lainnya mengalami dukungan keluarga kurang dan tidak mengalami gangguan citra tubuh. Proses terjadinya gangguan citra tubuh tidak hanya disebabkan oleh dukungan keluarga, namun ada beberapa faktor lain, seperti, Jenis kelamin, usia, pekerjaan, pendidikan dan tingkat pengetahuan. Hasil analisa 6 responden, 1 diantaranya menegah dan 5 sisanya mempunyai pengetahuan yang cukup. Dimana dengan mereka mempunyai tingkat pengetahuan yang cukup sehingga mereka lebih bisa menerima kondisi yang terjadi.

Sedangkan dari dari 32 orang yang mengalami dukungan keluarga baik, 18 orang $(23,1 \%)$ mengalami citra tubuh positif.Karena dengan adanya dukungan 
keluarga yang baik responden lebih bisa menerima kondisi yangterjadi sehingga tidak mengalami gangguan citra tubuh. Sedangkan 14 responden $(17,9 \%)$ lainnya tingkat dukungan keluarga baik tetapi mengalami gangguan citra tubuh. Setelah di analisa, ternyata dari 14 responden, 11 responden berpendidikan dasar. sehingga perilaku dan perepsi tentang kesehatan berbeda dengan responden yang berpendidikan tinggi. Responden yang berpendidikan dasar tingkat pengertahuannya kurang luas sehingga cenderung kurang mengetahui permasalahan yang dihadapi, sehingga muncul presepsi negatif tentang dirinya dan menyebabkan gangguan citra tubuh.

Berdasarkan hasil penelitian dapat disimpulkan bahwa bahwa semakin baik tingkat dukungan keluarga akan lebih memotivasi pasien kusta sehingga mereka lebih bisa menerima kondisinya dan penderita kusta tidak mengalami gangguan citra tubuh/ citra tubuh negatif.

\section{KESIMPULAN}

1. Hampir setengah dari responden memiliki dukungan keluarga kurang.

2. Sebagian besar responden memiliki citra tubuh negatif.

3. Ada hubungan antara dukungan keluarga dengan gangguan citra tubuh pada penderita kusta.

\section{DAFTAR PUSTAKA}

Azwar, MD (2012) Penyakit Kusta Sebuah Pendekatan Klinis. Surabaya: Brilian Internasional

Dinkes (2013) Data Kementrian Kesehatan 2011.Jawa Timur. Dinas Propinsi Jawa Timur

Djuanda, Adhi, dkk (2011) Ilmu Penyakit Kulit dan Kelamin. Jakarta : Fakultas Kedokteran Universitas Indonesia

Friedman, M. Marlyn (1998) Keperawatan Keluarga: Teori dan Praktik. Jakarta: EGC
Halim P. W,Ross WF. (2000) Penyakit Kusta Edisi Ke-2. Jakarta: Fakultas Kedokteran Universitas Indonesia

Keliat, BA. (2009) Proses Keperawatan Kesehatan Jiwa.Jakarta: EGC

Kementrian Kesehataan RI (2013) Buletin data dan jendela kesehatan volume 2. Jakarta: Tri wulan

Kosasih, A. Kusta. dalam Djuanda,A. (2011) Ilmu Penyakit Kulit dan Kelamin.Jakarta: Fakultas Kedokteran Universitas Indonesia

Martodiharjo dan Susanto (2006) Kusta. Jakarta

Notoatmojo (2005) Metodologi Penelitian Kesehatan (Edisi Revisi). Jakarta: Salemba Medika

Soebono \& Suharyanto (2006) Faktorfaktor yang mempengarauhi ketidakteraturan berobat pada penderita kusta di Kabupaten Blora. http://i-lib.ugm.ac.id

Stuart, Gail \& Sundeen, Sandra (2005) Buku Ajar Keperawatan Jiwa. Jakarta: EGC

Stuart, Gail W.(2007) Buku Saku Keperawatan Jiwa. Jakarta: EGC

Sugiyono (2011) Metode Penelitian Kuantitatif Kualitatif dan $R \& D$. Bandung: Alfabeta

Subekti (2005) Faktor-faktor yang berhubungan dengan tingkat kecacatan pada penderita kusta (Kajian di Kabupaten Sukoharjo). Yogyakarta: Universitas Gajah Mada

Zulkifli (2003)Penyakit Kusta dengan Masalah yang Ditimbulkan. Medan : Fakultas Kedokteran Universitas Sumatra Utara

Wald, J \& Alvaro, R. (2004) Faktorfaktor psikologis dalam pekerjaan yang berhubungan dengan amputasi: Pertimbangan untuk rehabilitasi konselor. Diambil tanggal 3 November 2014 dari http://findarticles.com/p/articles/

WHO (1995) A Guide to Leprosy Control. Edisi ke-1. World Health Organizatian Geneva 